\title{
Positive Youth Development, Life Satisfaction and Problem Behaviour Among Chinese Adolescents in Hong Kong: A Replication
}

\author{
Rachel C. F. Sun • Daniel T. L. Shek
}

Accepted: 9 January 2011/Published online: 19 January 2011

(C) The Author(s) 2011. This article is published with open access at Springerlink.com

\begin{abstract}
The purpose of this replication study was to examine the relationships among life satisfaction, positive youth development and problem behaviour. The respondents were 7,151 Chinese Secondary 2 (Grade 8) students (3,707 boys and 3,014 girls) recruited from 44 schools in Hong Kong. Validated assessment tools measuring positive youth development, life satisfaction and problem behaviour were used. As predicted, positive youth development was positively correlated with life satisfaction, and positive youth development and life satisfaction were negatively correlated with adolescent problem behaviour. Based on a series of structural equation models, the present findings replicated the previous findings that adolescents with a higher level of positive youth development were more satisfied with life and had lesser problem behaviour, with higher level of life satisfaction and lower level of problem behaviour mutually influencing each other. These replicated findings provide a further advance in the literature on positive youth development, particularly in the Chinese context. Implications for future research and intervention were discussed.
\end{abstract}

Keywords Adolescents - Positive youth development - Life satisfaction · Problem behaviour · Replication

\section{Introduction}

In contrast to the focus on adolescent pathologies and problems, positive youth development emphasizes on talents, strengths, potentials, and positive attributes of young people (Child Trends 2003; Damon 2004). Although there are different views of the nature of positive youth development qualities in the literature, it is commonly referred to the

R. C. F. Sun $(\bowtie)$

Faculty of Education, The University of Hong Kong, Pokfulam Road, Pokfulam, Hong Kong e-mail: rachels@hku.hk

D. T. L. Shek

Department of Applied Social Sciences, The Hong Kong Polytechnic University, Hung Hom, Kowloon, Hong Kong 
competencies of (a) self-understanding and cultivating discipline, (b) working with others, communicating, cooperating, negotiation, and building relationships, (c) coping, adapting, and being responsible, and (d) making good judgments, evaluating, making decisions and problem solving. Catalano et al. (2004) pointed out that there are fifteen basic youth development constructs, including bonding, social competence, emotional competence, cognitive competence, behavioural competence, moral competence, self-efficacy, prosocial norms, resilience, self-determination, spirituality, clear and positive identity, beliefs in the future, prosocial involvement and recognition for positive behaviour.

There are theoretical propositions maintaining that positive youth development influences the well-being and health outcomes of an individual. For example, in the model developed by Lent (2004), positive development attributes such as self-efficacy affect life satisfaction. The social learning theory proposed by Bandura (1997) also posited that selfefficacy contributes to positive health outcomes and adjustment. In the existential literature, logotherapy suggests that meaning in life fills "existential vacuum" thus leaving no space for the development of psychopathology. Empirically, there are research findings showing that positive youth development attributes, like owning bonding and social roles, were closely related to adolescent life satisfaction (Paxton et al. 2006). Several positive youth development constructs, like social and emotional competencies (Ciarrochi et al. 2003), academic and social self-efficacy (Vecchio et al. 2007), prosocial motivation and behaviour (Caprara and Steca 2005; Gebauer et al. 2008), spirituality and religiosity (Laudet and White 2008; Zullig et al. 2006), and mastery and ethnic identity (Sam 1998) were found to act as significant predictors of life satisfaction.

As adolescents having weak resilience, poor psychosocial competencies, blurred selfidentity and low self-efficacy are likely to have poor developmental outcomes, there are theoretical accounts regarding the influence of positive youth development on mitigating adolescent problem behaviour. Based on the concepts of protective factors in resilience literature, it can be conjectured that internal resources such as psychosocial competencies and external resources such as bonding (e.g., Jessor et al. 2003) would protect individuals from life stresses, thus minimizing the occurrence of problem behaviour. There are researches showing that positive youth development was negatively relate to problem behaviour, such as substance abuse and delinquency. In North America, Catalano et al. (2004) showed that around $96 \%$ of the 25 well-evaluated positive youth development programs reduced problem behaviour; whereas in Hong Kong, Shek (2010a) found that positive youth behaviour was negatively related to behavioural intention to engage in problem behaviour among Chinese adolescents.

Besides positive youth development, life satisfaction also has an inverse relationship with adolescent problem behaviour. Studies showed that life satisfaction was negatively associated with sexual risk-taking behaviours (Valois et al. 2002), substance abuse (Desousa et al. 2008), and violence and aggression (MacDonald et al. 2005) among adolescents. Heavy substance or tobacco use in adolescence, in turn, contributed to lower levels of life satisfaction, relationship satisfaction, and physical and mental health in adulthood longitudinally (Fergusson and Boden 2008; Georgiades and Boyle 2007).

There are several limitations in the literature pertinent to the relationships among positive youth development, life satisfaction and adolescent problem behaviour. First, existing findings on the predictive effects of positive youth development on life satisfaction and problem behaviour are quite piecemeal, and few researchers have included multiple and validated measures of positive youth development in one single study (Sun and Shek 2010). Shek (2010b) also pointed out that compared with other age groups such as old people, there are comparatively fewer studies on the quality of life of children and adolescents. 
Second, in contrast to the existence of studies examining the effect of positive youth development on life satisfaction, there are few studies on how life satisfaction may contribute to positive youth development. In the review conducted by Diener et al. (1999), it was observed that while there were many studies on the demographic correlates of life satisfaction, research findings on the effect of life satisfaction on positive youth development were almost non-existent. As life satisfaction constitutes inner psychological resources (e.g., emotional stability), it is hypothesized that life satisfaction would affect positive youth development, such as social relationship and prosocial involvement.

Third, while there are different possibilities pertinent to the inter-relationships among positive youth development, life satisfaction and problem behaviour, this is a neglected area and there are few related research studies. For example, in their review of research on subjective well-being in the past three decades, Diener et al. (1999) could not unearth any systematic studies on the relationships among positive youth development, life satisfaction and problem behaviour. The inter-relationships among these variables would become more complicated when researchers treat life satisfaction as a mediator between positive youth development and adolescent problem behaviour. In the existing literature, many studies treated life satisfaction either as an outcome variable (e.g., Gebauer et al. 2008) or as a predictor (e.g., Heisel and Flett 2004), while several studies examined the mediating influence of life satisfaction on problem behaviour (McKnight et al. 2002; Suldo and Huebner 2004). Pavot and Diener (2008) also pointed out that "investigators have only recently begun to focus on outcomes that are predicted by life satisfaction. Future research needs to focus not only on the factors that contribute to the experience of life satisfaction, but also on the effects life satisfaction has on future behaviour and life outcomes." (p. 147).

Finally, although integrative models were tested by using structural equation modelling or hierarchical regressions to demonstrate the predictive effect of positive youth development on problem behaviour (Jessor et al. 2003; Lent et al. 2005), these cross-sectional studies did not examine the reverse predictive effect of problem behaviour on positive youth development. This research gap can be filled by testing the predictive relationship of positive youth development to life satisfaction and problem behaviour, as well as possible reverse or even bidirectional relationships in one single study.

To address this, Sun and Shek (2010) examined the relationships among life satisfaction, positive youth development and problem behaviour in a total of 7,975 Secondary 1 (Grade 7) students. As predicted, positive youth development and life satisfaction were positively correlated, and both of them had negative relationships to problem behaviour. Based on latent variable analyses, the findings suggest that adolescents with higher levels of positive youth development are more satisfied with life and have lesser problem behaviour, with a bidirectional relationship between life satisfaction and problem behaviour. Although the findings are pioneering, there is still a question of whether their findings could be replicated over time.

In the realm of science, replication has been regarded as an important strategy for confirming the validity of scientific investigations. Fahs et al. (2003) pointed out that "replication of research is essential to the building and continued development of the scientific basis of any discipline." (p.67). Reese (1999) similarly reminded that "although replication research is often disvalued as 'derivative', it can be an invaluable aid to scientific progress." (p.1). King (1995) also stated that "the most common and scientifically productive method of building on existing research is to replicate an existing finding-to follow the precise path taken by a previous researcher, and then improve the data or methodology in one way or another." (p.445). The role of replication in guarding against uncritical acceptance of research findings is also proposed by different researchers. Singh 
et al. (2003) asserted that "replication serves the fundamental role of protecting against the uncritical acceptance of empirical results. It is thus as important as the core academic practices of peer review and publication of research, and is necessary for any stream of scientific inquiry to develop the requisite rigor of a science." (p.533-534). Hubbard and Vetter (1996) similarly argued that replication "protects against the uncritical assimilation of specious empirical results into the literature. Replications with extensions serve to determine the scope and limits of empirical findings by seeing if they can be generalized to other populations, contexts, time periods, geographical areas, and so on.” (p.153). It is necessary to realize that studies utilizing multivariate statistics easily capitalize on chance. Therefore, replication is always important.

Against the above background, the present study attempted to replicate the findings reported by Sun and Shek (2010) using the same cohort of participants over time. Consistent with their findings, the general hypotheses of this study were: (1) positive youth development would be positively related to life satisfaction; (2) positive youth development would be negatively related to adolescent problem behaviour; and (3) life satisfaction would be negatively related to adolescent problem behaviour. Besides, the following models were tested:

- Model 1: It was hypothesized that positive youth development would have a positive effect on life satisfaction but a negative effect on problem behaviour, with life satisfaction partially mediating the impact of positive youth development on problem behaviour. (i.e., partial mediation model)

- Model 2: It was hypothesized that positive youth development would have a positive effect on life satisfaction, and that life satisfaction would have a negative effect on problem behaviour. (i.e., full mediation model)

- Model 3: It was hypothesized that adolescent problem behaviour would have negative effects on positive youth development as well as life satisfaction, and that life satisfaction would have a positive effect on positive youth development. (i.e., reverse effect model)

- Model 4: It was hypothesized that positive youth development and life satisfaction would have a bidirectional relationship. Both positive youth development and life satisfaction would have negative effects on problem behaviour. (i.e., non-recursive model with a bidirectional path between exogenous and one endogenous variables)

- Model 5: It was hypothesized that positive youth development would have a bidirectional relationship with life satisfaction and a negative effect on problem behaviour. Also, life satisfaction and problem behaviour would have a bidirectional relationship. (i.e., non-recursive model with two bidirectional paths)

- Model 6: It was hypothesized that positive youth development would have a positive effect on life satisfaction and a negative effect on problem behaviour, with life satisfaction and problem behaviour having a bidirectional relationship. (i.e., nonrecursive model with a bidirectional path between two endogenous variables)

\section{Method}

\subsection{Participants and Procedure}

Sun and Shek (2010) reported findings based on the initial cross-sectional data of a longitudinal evaluation of the Project P.A.T.H.S. (see Shek and Sun 2009 for details of the 
project) in Hong Kong in 2006-07 school year. The respondents were 7,975 Secondary 1 (Grade 7) students from 48 secondary schools, and they responded to an objective outcome evaluation questionnaire at the beginning of the school year. In the present study, the respondents were the same cohort promoted to Secondary 2 (Grade 8) level in 2007-08 school year. As three schools had withdrawn, there were 7,151 respondents, and they completed the same objective outcome questionnaire at the beginning of the school year. Among these respondents, 3,707 (51.8\%) were boys and 3,014 (42.1\%) were girls, with the remaining $6.1 \%$ not reporting their gender. A majority of the students reported their age as $13(59.8 \%), 14(17.2 \%)$ or $12(11.2 \%)$.

Similar to the previous study, data were collected at the schools by trained research staff and/or school teachers with adequate advance briefings. Parental and school consent were obtained prior to data collection. At the time of data collection, student consent was sought, the purpose of the study was mentioned, and the confidentiality of the data collected was repeatedly emphasized to all students. After giving instructions, adequate time was provided for all students to respond to all scales in the questionnaires in a self-administration format. No students refused to complete the questionnaires.

\subsection{Instruments}

\subsubsection{Assessment of Positive Youth Development}

Positive youth development was measured by the modified Chinese Positive Youth Development Scale (Shek et al. 2008), on a six-point rating scale (except spirituality subscale using a seven-point rating scale). A detailed description of the scale and its psychometric properties can be found in Shek et al. (2007) and Shek and Ma (2010). The scale examines 15 positive youth development constructs (Table 1). Global positive youth development was obtained by averaging the mean of each subscale.

\subsubsection{Assessment of Life Satisfaction}

Life satisfaction was measured by the five-item Life Satisfaction Scale on a six-point rating scale (Diener et al. 1985), which assesses global judgment of one's quality of life. The Chinese translation was found to have acceptable psychometric properties (Shek 2004).

\subsubsection{Assessment of Problem Behaviour}

Problem behaviour was measured by three subscales: substance abuse is an eight-item measure using a seven-point rating scale; delinquency is a 12-item measure using a seven-point rating scale; and intention to engage in problem behaviour is a five-item measure using a four-point rating scale. These subscales were found to have acceptable construct validity (Shek 2004). Global problem behaviour was obtained by averaging the mean of each subscale.

\subsection{Data Analyses}

The hypothetical models were tested by structural equation modelling (SEM) via LISREL 8.80 (Byrne 1998; Jöreskog and Sörbom 2006). SEM is an advanced statistical technique which combines factor analysis and multiple regression analysis. And it is used to analyze structural relationships between measured variables and latent variables. In SEM, one or 


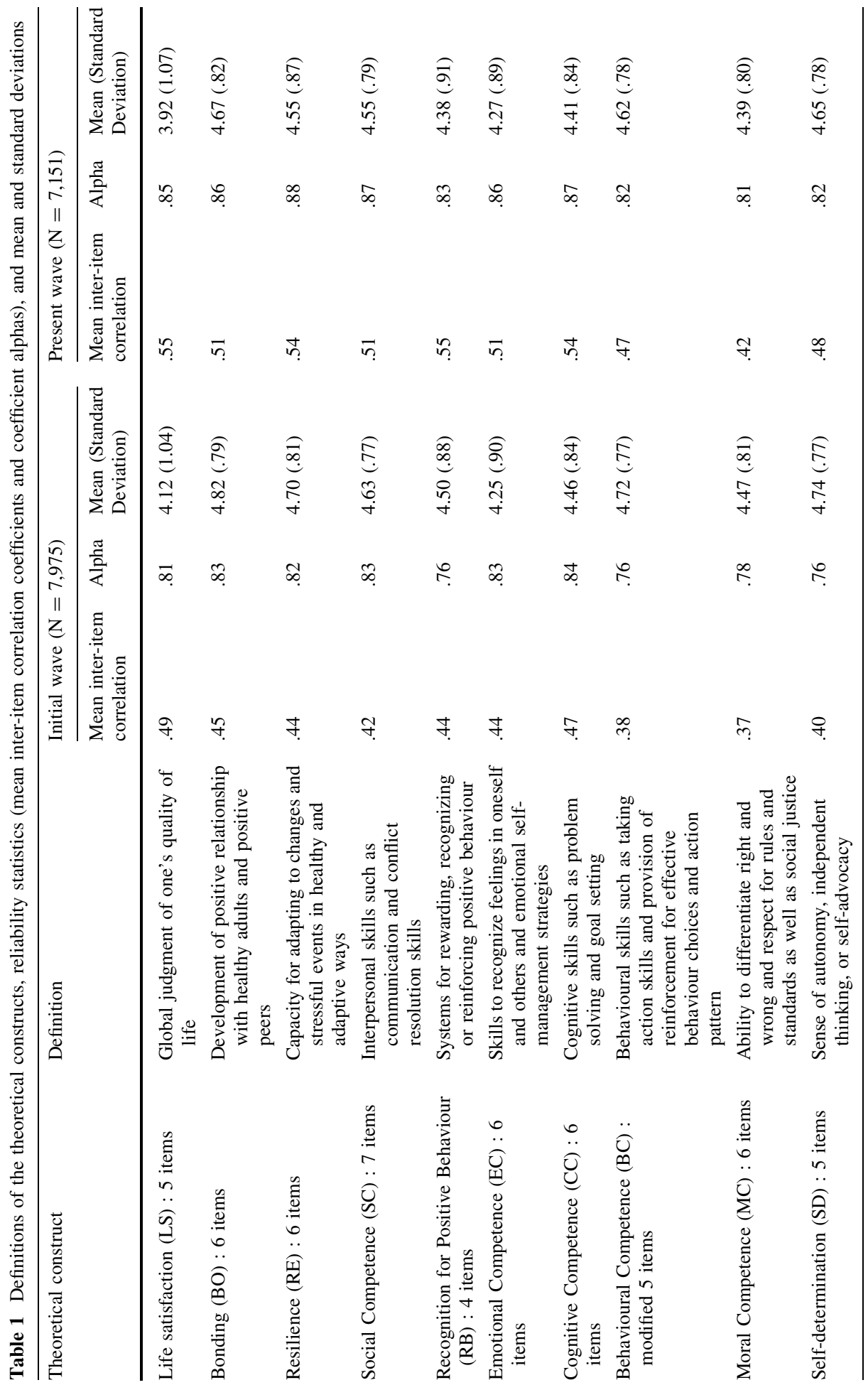




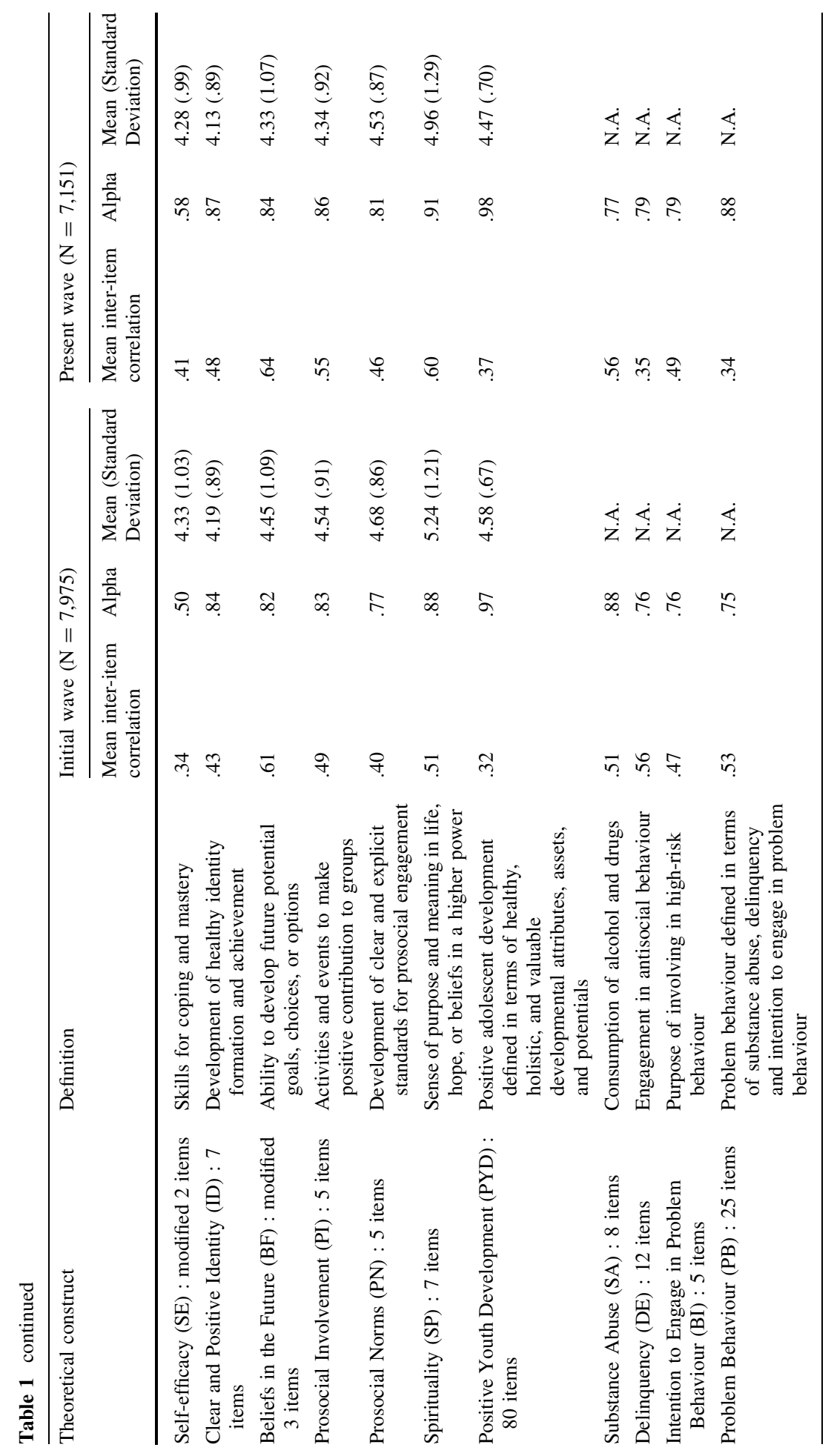


more competing models are tested and different goodness of fit indices can be used to show which model fits better than others (Hu and Bentler 1999). A survey of the literature shows that SEM is commonly used to examine survey data (Schumacker and Lomax 2004).

One assumption of using maximum likelihood estimation in SEM is multivariate normal distribution. In case this assumption cannot be met, there are several solutions, including the use of other estimation procedures such as Weighted Least Squares (WLS), Diagonally Weighted Least Squares (DWLS) and Robust Maximum Likelihood (RML). Many researchers suggested that the scaled chi-square based on the method developed by Satorra and Bentler appears to be a reasonable approach to dealing with nonnormality in samples (Curran et al. 1996; Finney and DiStefano 2006; Hu et al. 1992). In LISREL 8.80, Robust Maximum Likelihood (RML) can be used to estimate the free parameters in models based on non-normal data. PRELIS 2.80 gives the estimations of polychoric covariance and asymptotic covariance matrices, which allow RML to provide the Satorra-Bentler scaled chi-squares in the LISREL 8.80 solutions for estimating the non-normal data.

Evaluation of model fit was based on multiple criteria, including the theoretical meaningfulness of the model, absolute-fit indices (how well a model fits the data, without comparing to a baseline model), incremental fit measures (how much better the model fits than a baseline model) and model cross-validation (how the model can be replicated with an independent sample). Absolute fit indices include Satorra-Bentler scaled chi-square $\left(\chi^{2}\right)$, root mean square error of approximation (RMSEA), goodness-of-fit index (GFI), and standardized root mean residual (SRMR). Incremental fit measures include the non-normed fit index (NNFI) and the comparative fit index (CFI). For model cross-validation, the total sample was split randomly into two sub-samples for model exploration and validation respectively, and a cross-validation index (CVI) was computed to indicate discrepancies among the sub-samples (Hu and Bentler 1999).

\section{Results}

Reliability analyses showed that all the scales and subscales except the self-efficacy subscale were highly reliable, i.e., they had alpha coefficients of .77 or above (Table 1).

Analyses based on Pearson correlations showed that all variables were correlated in the expected directions (with a two-tailed multistage Bonferroni correction; Table 2). Different measures of positive youth development and global positive youth development were positively correlated with life satisfaction, and all of them were negatively correlated with substance abuse, delinquency, intention to engage in problem behaviour, and global problem behaviour.

As expected, variables were normally distributed, except substance abuse and delinquency of problem behaviour variables having the values of skewness greater than 2 and the values of kurtosis greater than 7 (West et al. 1995). To deal with data's non-normality, Robust Maximum Likelihood (RML) method, with Satorra-Bentler scaled chi-square, was used in the present study. In two-step modelling (Anderson and Gerbing 1988), the measurement models of the positive youth development, life satisfaction and problem behaviour were tested first. Results showed that the fifteen-indicator positive youth development fit the data [Satorra-Bentler scaled $\chi^{2}(90, n=3575)=2075.82$; RMSEA $=0.08$; GFI $=0.85$; $\mathrm{SRMR}=0.044 ; \mathrm{NNFI}=0.98 ; \mathrm{CFI}=0.98 ; \mathrm{CVI}=1.14]$ and that the three-indicator problem behaviour had excellent fit indices [Satorra-Bentler scaled $\chi^{2}(0, n=3575)=0$; $\mathrm{CVI}=0.01]$. The construct validity of both scales was supported. Similar to Sun and Shek's study (2010), the measurement model of the five-indicator life satisfaction did not fit well. 


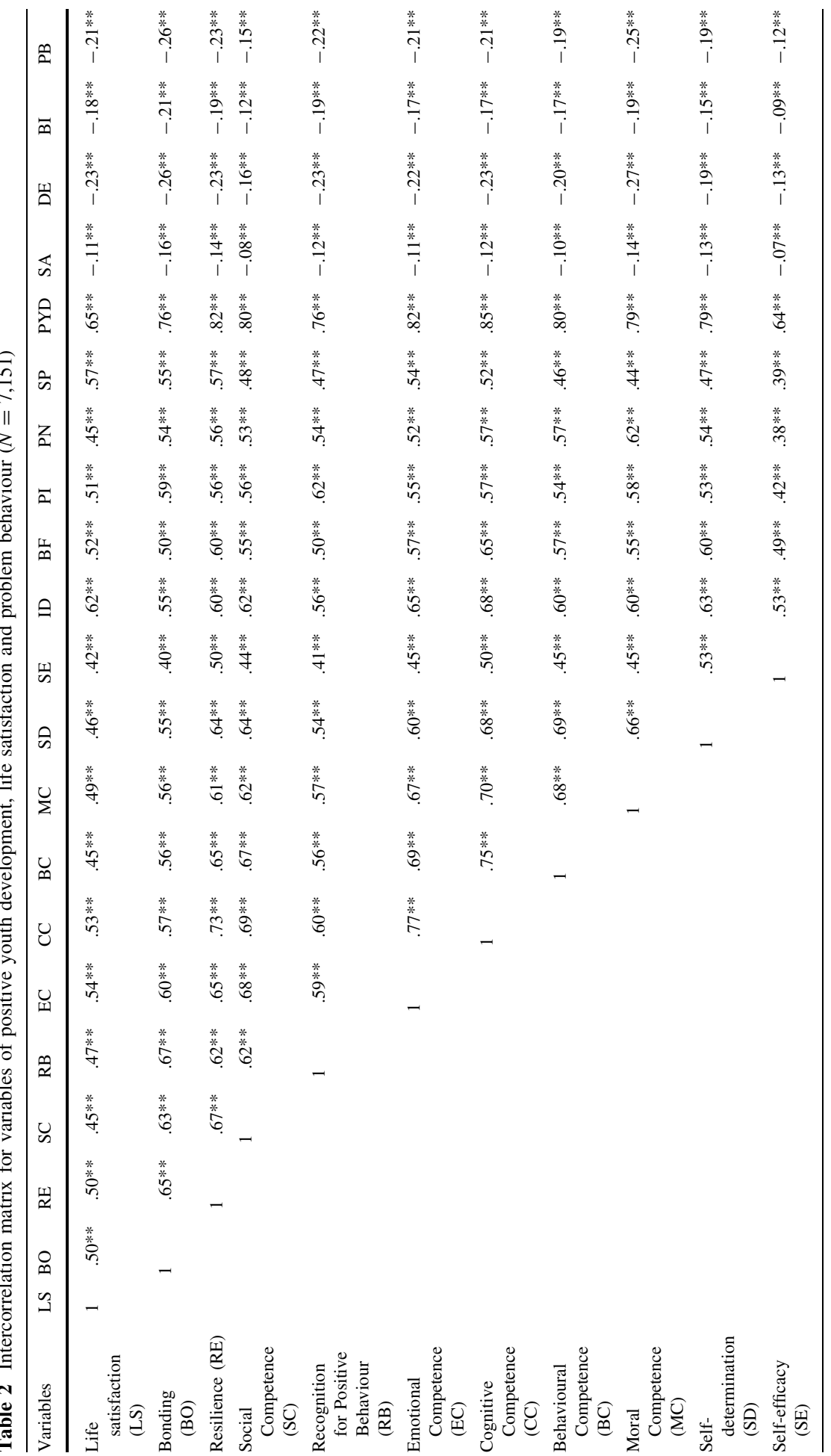




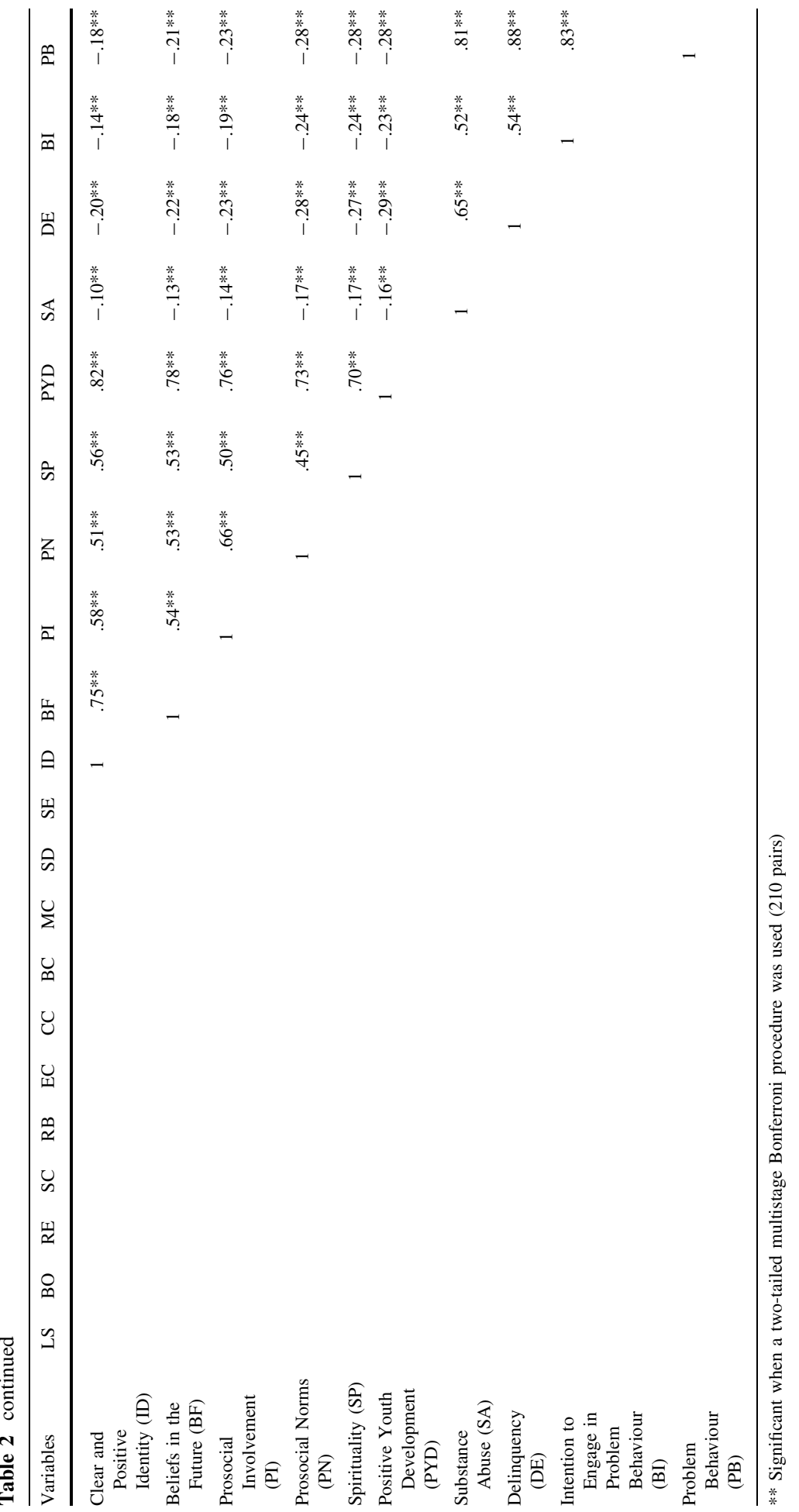


After dropping item 5, the modified four-indicator life satisfaction had a significant $\chi^{2}$-difference $\left(\Delta \chi^{2}=231.4, \Delta d f=3, p<0.01\right)$, and good fit [Satorra-Bentler scaled $\chi^{2}(2, n=3575)=8.53$; RMSEA $=0.03$; GFI $=1.00 ;$ SRMR $=0.009$; NNFI $=1.00$; $\mathrm{CFI}=1.00 ; \mathrm{CVI}=0.02]$.

To examine the structural model, the six hypothetical models were tested and compared. The one showing optimal fit was selected to represent the final model.

\subsection{Step (1): Testing Model 1}

As shown in Table 3, the fit indices of Model 1 were adequate [Satorra-Bentler scaled $\chi^{2}$ $(206, n=3575)=3243.90 ;$ RMSEA $=0.06 ;$ GFI $=0.86 ;$ SRMR $=0.047 ;$ NNFI $=$ $0.98 ; \mathrm{CFI}=0.98$; CVI $=12.78$ ] (see Fig. 1). Model 1 explained $42 \%$ of the variance in life satisfaction and $8 \%$ of the variance in problem behaviour.

\subsection{Step (2): Testing Model 2 with Model 1}

The fit indices of Model 2 were adequate [Satorra-Bentler scaled $\chi^{2}$ (207, $n=$ $3575)=3253.85$; RMSEA $=0.06$; GFI $=0.86$; $\mathrm{SRMR}=0.052 ; \mathrm{NNFI}=0.98 ; \mathrm{CFI}=$ 0.98 ; CVI $=12.58$ ] (Table 3; see Fig. 2). Model 2 explained $42 \%$ of the variance in life satisfaction and $7 \%$ of the variance in problem behaviour. When compared with Model 1 ,

Table 3 Goodness-of-fit indices of structural models $(N=7,151)$

\begin{tabular}{|c|c|c|c|c|c|c|c|c|}
\hline Structural model & $\chi^{2}(d f)$ & $\Delta \chi^{2}(\Delta d f)$ & RMSEA & GFI & SRMR & NNFI & CFI & CVI \\
\hline (1) Model 1 & $3243.90(206)$ & & 0.06 & 0.86 & 0.047 & 0.98 & 0.98 & 12.78 \\
\hline (2) Model 2 & $3253.85(207)$ & & 0.06 & 0.86 & 0.052 & 0.98 & 0.98 & 12.58 \\
\hline Model 2 Vs. Model 1 & & $9.95(1)^{* *}$ & & & & & & \\
\hline (3) Model 3 & $3243.90(206)$ & & 0.06 & 0.86 & 0.047 & 0.98 & 0.98 & 1.45 \\
\hline Model 3 Vs. Model 1 & & N.A. & & & & & & \\
\hline (4) Model 4 & $3265.31(206)$ & & 0.06 & 0.85 & 0.22 & 0.98 & 0.98 & 1.61 \\
\hline Model 4 Vs. Model 1 & & N.A. & & & & & & \\
\hline (5) Model 5 & $3240.20(206)$ & & 0.06 & 0.86 & 0.21 & 0.98 & 0.98 & 1.61 \\
\hline Model 5 Vs. Model 1 & & N.A. & & & & & & \\
\hline (6) Model 6 & 3209.19(206) & & 0.06 & 0.86 & 0.051 & 0.98 & 0.98 & 12.90 \\
\hline Model 6 Vs. Model 1 & & N.A. & & & & & & \\
\hline
\end{tabular}

A better fitting model was judged by Satorra-Bentler scaled $\chi^{2}$, RMSEA $<0.08$, GFI, NNFI and CFI $>0.90$, SRMR $<0.05$, a low CVI value, and a significant $\chi^{2}$-difference for nested models $(* * p<0.01)$

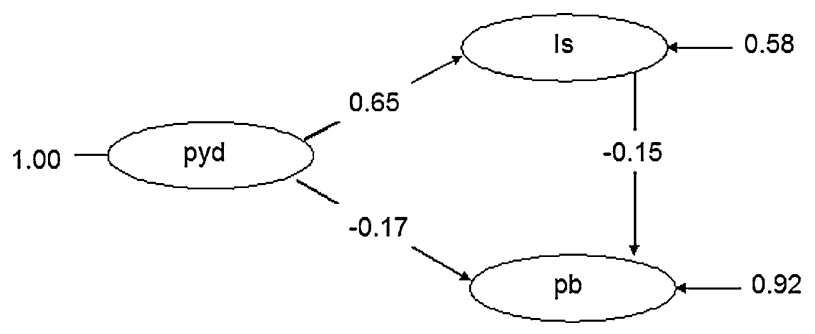

Fig. 1 Tested model 1: partial mediation model 


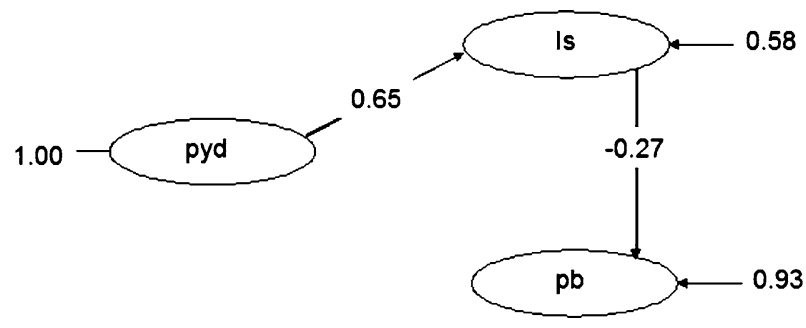

Fig. 2 Tested model 2: Full mediation model

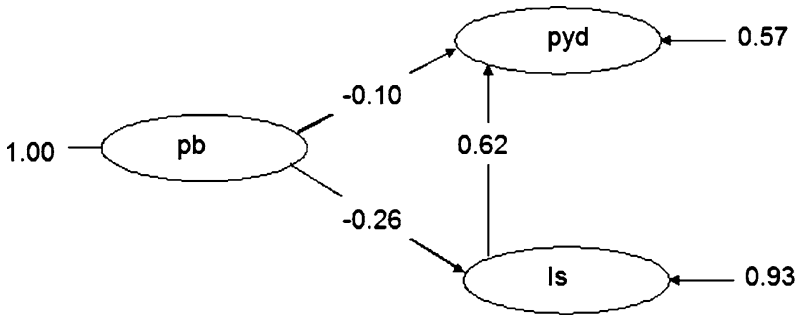

Fig. 3 Tested model 3: Reverse effect model

although Model 2's CVI was a bit lower, it had a higher Satorra-Bentler scaled $\chi^{2}$. Therefore, Model 1 was preferred, which suggested that life satisfaction partially mediated the relationship of positive youth development to problem behaviour. It was used as a baseline model for further model comparison.

\subsection{Step (3): Testing Model 3 with Model 1}

The fit indices of Model 3 were also adequate [Satorra-Bentler scaled $\chi^{2}(206, n=3575)=$ 3243.90; $\quad$ RMSEA $=0.06 ; \quad$ GFI $=0.86 ; \quad$ SRMR $=0.047 ; \quad$ NNFI $=0.98 ; \quad$ CFI $=0.98$; $\mathrm{CVI}=1.45$ ] (Table 3; see Fig. 3). Model 3 explained $43 \%$ of the variance in positive youth development and $6.8 \%$ of the variance in life satisfaction. Although Model 3 had a lower CVI value, Model 3 was not preferred because the theoretical support and empirical evidences maintaining the relationships in this reverse effect model (Diener et al. 1999; Georgiades and Boyle 2007) were not as strong as those of Model 1. Therefore, Model 1 was preferred.

\subsection{Step (4): Testing Model 4 with Model 1}

When compared with Model 1, although Model 4 had a lower CVI, it had higher SatorraBentler scaled $\left[\chi^{2}(206, n=3575)=3265.31\right]$ and a poor SRMR $(0.22)$ (Table 3; see Fig. 4). It suggested that the bidirectional relationship between positive youth development and life satisfaction was not preferred. Therefore, Model 4 was rejected.

\subsection{Step (5): Testing Model 5 with Model 1}

When compared with Model 1, although Model 5 had a lower CVI, it had a poor SRMR (0.21) (Table 3; see Fig. 5). It suggested that the non-recursive model with two bidirectional paths was not preferred. Therefore, Model 5 was rejected. 


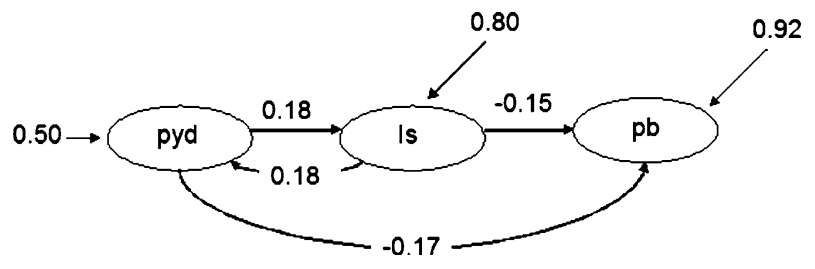

Fig. 4 Tested model 4: Non-recursive model with a bidirectional path between exogenous and one endogenous variables

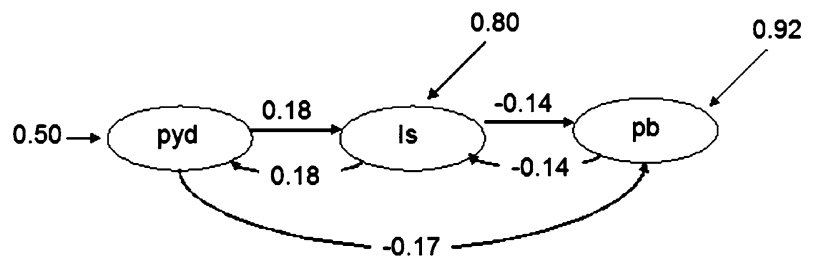

Fig. 5 Test model 5: Non-recursive model with two bidirectional paths. pyd positive youth development, $l s$ life satisfaction, $p b$ problem behaviour

\subsection{Step (6): Testing Model 6 with Model 1}

The fit indices of Model 6 were adequate [Satorra-Bentler scaled $\chi^{2}$ (206, $n=3575)=3209.19 ; \quad$ RMSEA $=0.06 ;$ GFI $=0.86 ; \quad \mathrm{SRMR}=0.051 ; \mathrm{NNFI}=0.98$; $\mathrm{CFI}=0.98$; CVI $=12.90$ ] (Table 3; see Fig. 6). When compared with Model 1, although Model 6's CVI was a bit higher, it had a lower Satorra-Bentler scaled $\chi^{2}$. Hence, Model 6 was preferred and accepted as the final model in the present study because it had the most optimal fit indices, although it is noteworthy that it was only slightly better than Model 1 . Moreover, the direct effects of positive youth development on both life satisfaction and problem behaviour, and the reciprocal relationship between life satisfaction and problem behaviour, have been supported by different studies (e.g., Catalano et al. 2004; Desousa et al. 2008; Fergusson and Boden 2008; Sun and Shek 2010). Such a non-recursive model explained $46 \%$ of the variance in life satisfaction and $11 \%$ of the variance in problem behaviour. The variances explained by this model were better than those of Model 1 .

All in all, the findings supported the original hypotheses: (1) positive youth development was positively related to life satisfaction; (2) positive youth development was negatively related to adolescent problem behaviour; and (3) life satisfaction was negatively related to adolescent problem behaviour. It should be noted that the correlations between positive youth development and problem behaviour and between life satisfaction and problem behaviour were comparatively weaker, although they were significant. Similar to many previous findings in the West (e.g., Ciarrochi et al. 2003; Laudet and White 2008; Paxton et al. 2006; Vecchio et al. 2007), the present study found that Chinese adolescents having better bonding, social competence, emotional competence, behavioural competence, self-efficacy, prosocial behaviour and spirituality were more likely to have higher levels of life satisfaction; and adolescents having higher levels of life satisfaction were less likely to engage in problem behaviour (e.g., Desousa et al. 2008; MacDonald et al. 2005). In addition to this, the present study further showed that resilience and beliefs in the future were other significant positive youth development constructs associating with life 


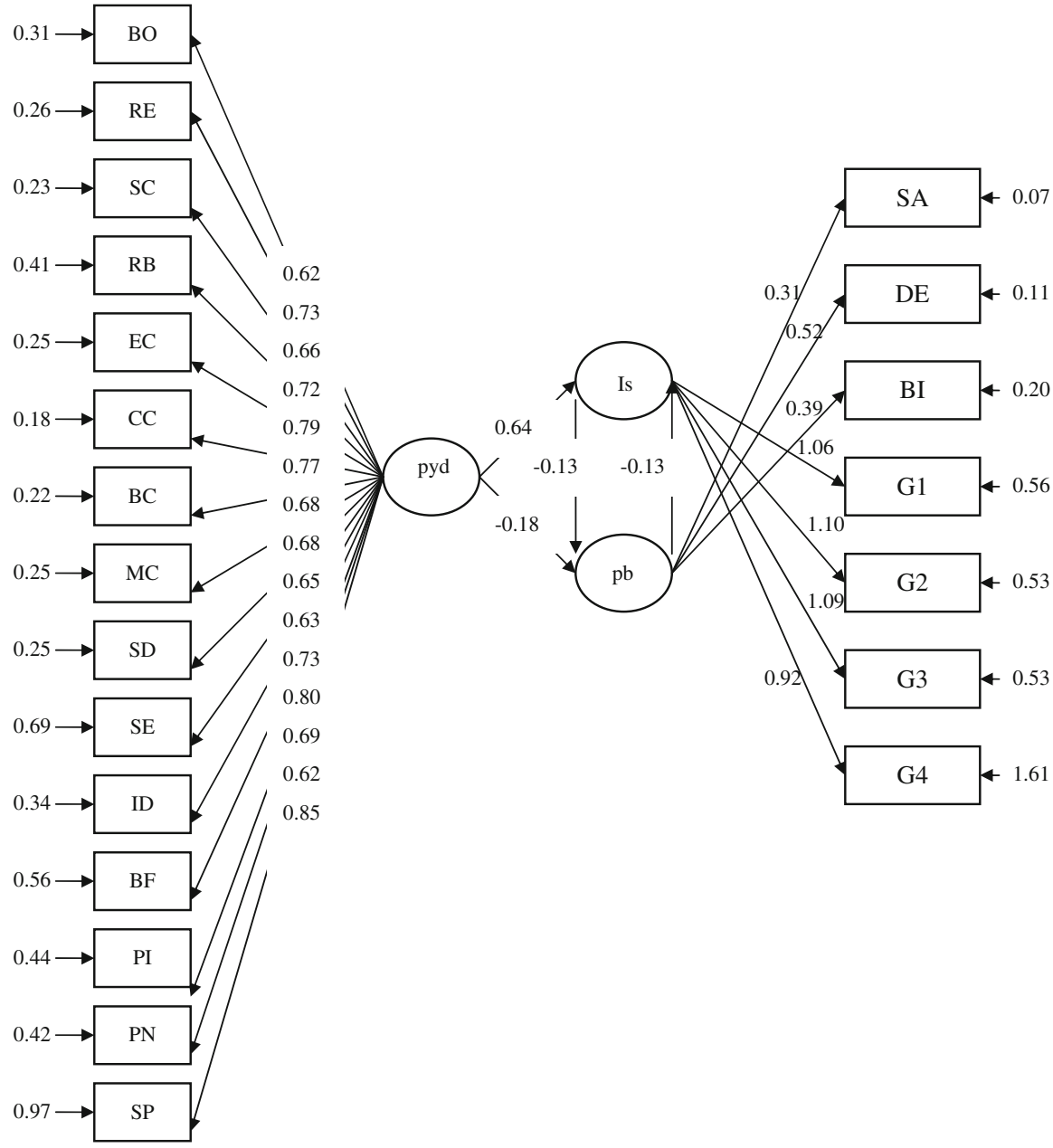

Fig. 6 Tested model 6: Non-recursive model with a bidirectional path between two endogenous variables. pyd positive youth development, $l s$ life satisfaction, $p b$ problem behaviour, $B O$ bonding, $R E$ resilience, $S C$ social competence, $R B$ recognition for positive behaviour, $E C$ emotional competence; $C C$ cognitive competence, $B C$ behavioural competence, $M C$ moral competence, $S D$ self-determination, $S E$ self-efficacy, $I D$ positive identity, $B F$ beliefs in the future, $P I$ prosocial involvement, $P N$ prosocial norms, $S P$ spirituality, $S A$ substance abuse, $D E$ delinquency, $B I$ intention to engage in problem behaviour, G1-G4 4 indicators of Life Satisfaction Scale

satisfaction among adolescents. Particularly, positive identity and spirituality were closely associated with life satisfaction. More importantly, as Model 6 was found to be the optimal model, the vital importance in promoting positive youth development to enabling satisfaction with life and alleviating risk-taking behaviour among early adolescents is maintained. Moreover, the reciprocal relationship between life satisfaction and problem behaviour also pointed to the significance in cultivating adolescents' satisfaction with one's life to mitigate substance abuse and delinquency, as well as in preventing or reducing adolescents' anti-social behaviour to encourage appreciation and content with life. In short, the findings suggest that adolescents should equip themselves with higher levels of strength 
and more positive development attributes, particularly their beliefs in the future and spirituality (see Fig. 6), so as to appraise life optimistically and to behave oneself properly. Thus, the implication of these findings is that the Government should devise education and youth policies to promote positive youth development so that adolescent problem behaviour can be minimized. Actually, in the recent release of the Resource Kit on Anti-Drug Education in Schools (Narcotics Division 2010), one proposal is to implement a positive youth development program titled Project P.A.T.H.S. (Shek and Sun 2010a, b) with a view to reduce adolescent substance abuse in the long run.

\section{Discussion}

The main purposes of the present study were to replicate a previous study (Sun and Shek 2010) and to test the different models pertinent to the relationships among positive youth development, life satisfaction and problem behaviour in Chinese adolescents over time. Several unique features were highlighted in this study. First, due to the paucity of studies on the inter-relationships among positive youth development, life satisfaction and problem behaviour concurrently in both Western and Chinese contexts, it is an important addition to the literature. Second, as studies on adolescent quality of life are almost non-existent (Shek 2010b), this study took a community sample of Chinese early adolescents in Hong Kong. Third, the sample size was large and this large sample was followed up in a consecutive year. Fourth, validated assessment tools measuring positive youth development, life satisfaction and adolescent problem behaviour were employed. In fact, analyses supported the reliability and construct validity of the measures. Fifth, latent variables analyses were performed which permit comparison of different models and depiction of the predictive directionality of the variables. Although non-normal data were found for the problem behaviour data, the problem was handled by using asymptotic covariance matrix, Robust Maximum Likelihood estimation procedures and Satorra-Bentler scaled chi-square. Finally, it is an invaluable research study demonstrating the importance of replication.

By a series of model testing and comparison, the present findings further demonstrated the relationships among positive youth development, life satisfaction and problem behaviour in Chinese adolescents. It fills the research gap in the existing literature, which mainly examined the relationships among stressful life events/parenting, life satisfaction and problem behaviour among youths in the West (McKnight et al. 2002; Suldo and Huebner 2004). Consistent with the findings of Sun and Shek (2010), the present finding supported Model 6 which suggests that positive youth development predicts life satisfaction and problem behaviour, with life satisfaction and problem behaviour having a bidirectional relationship. Although the full and partial mediating role of life satisfaction (Model 1 and Model 2) showed adequate fit indices, suggesting that the mediating role of life satisfaction is plausible, they were comparatively inferior models. Most importantly, following the precise paths in testing the statistical models using latent variable analyses, the present findings are highly similar to those reported by Sun and Shek (2010), thus successfully replicating the previous findings. In conjunction with the previous findings, the present findings suggest that unidirectional path models may not be adequate in delineating the relationships among positive youth development, life satisfaction and adolescent problem behaviour. Furthermore, attention should be paid to the reciprocal relationships between life satisfaction and problem behaviour.

Unlike Sun and Shek's study (2010), Model 3 also obtained adequate fit indices in the present study. However, in this cross-sectional study, such a reverse effect model was not 
preferred for several reasons. First, it lacks concrete theoretical framework in supporting the influence of problem behaviour to life satisfaction and positive youth development, as well as the influence of life satisfaction to positive youth development. Second, existing empirical evidences of the prediction of problem behaviour to life satisfaction were limited to adult sample in longitudinal studies (Georgiades and Boyle 2007), and those of life satisfaction to positive youth development were even non-existent (Diener et al. 1999). In fact, the reverse effect model in the present study was hypothesized based on logical deduction and following that in Sun and Shek's study (2010), in order to allow testing of various potential relationships among the variables. The present findings propose that the predictive relationships of problem behaviour to life satisfaction and positive youth development are possible. However, longitudinal studies are highly recommended to further validate these predictive relationships.

Obviously, the present study reinforces the importance of replication in the area of quality of life research. Adopting a critical realist position, Tsang and Kwan (1999) argued that "although replication cannot yield certain conclusions, it does not follow that it is not desirable to conduct replicated studies or that replication has no epistemic significance. When a replication successfully confirms the findings of the original study, it provides at least some support for the theory concerned. If the two studies are far apart in time, the replication supports the temporal validity of the theory as well. When numerous replications in diverse circumstances are repeatedly successful, it is highly likely that the theory has hit upon some real structure or mechanism in the social world, barring an alternative nonrealist explanation of this success." (p.759). The present findings could highly replicate those of the previous study (Sun and Shek 2010) might be due to the fact that the same cohort was used in different points of time. However, it should be noted early adolescents are experiencing rapid changes. Though just 1 year distant, Secondary 2 (Grade 8) students are having different levels of developmental characteristics, such as adjustment to puberty, cognitive maturation, rapid expansion of social circle, increased stress, encountering higher levels of social expectations, and gradual detachment from the family, when comparing to those in their Secondary 1 (Grade 7) level. Therefore, the present findings obviously demonstrate the temporal validity of the findings reported by Sun and Shek (2010).

The present study is imperative for several reasons. First, although there are Western studies examining the associations between life satisfaction and problem behaviour, there are few Western studies examining the relationships among positive youth development, life satisfaction and problem behaviour simultaneously in a single study. Second, this is the second known scientific study in the Chinese communities using data collected in early adolescents in Hong Kong which successfully replicated the previous findings. As Chinese people constitutes roughly one-fifth of the population in the world, the recruitment of Chinese participants is important. The data in this study were collected within the context of the Project P.A.T.H.S. in Hong Kong which is a pioneer positive youth development in different Chinese communities. Noting that Hong Kong is just a Special Administrative Region, P.R.C. with roughly 7 million people and constitutes a small portion of Chinese people when comparing with roughly 1.3 billion people in mainland China, generalizability of the present findings to people in mainland China should proceed with caution. Nevertheless, the present findings could serve as an important pointer for future research on Chinese adolescents. Third, SEM is a statistical technique used to delineate the relationships among positive youth development, life satisfaction and problem behaviour, of which the hypotheses and hypothetical models were developed based on theoretical support and empirical evidences. The final model was selected with reference to both theoretical meaningfulness of the model and statistical fit indices. The study by Sun and Shek 
(2010) was based on Secondary 1 (Grade 7) students while the present study was based on Secondary 2 (Grade 8) students. The findings showed that the relationships amongst positive youth development, life satisfaction and problem behaviour are rather stable in early adolescence years. This is a ground breaking finding which has not been reported in the literature. Finally, although the present findings are similar to the findings reported in Sun and Shek (2010), the replicated findings do not imply that the findings are unimportant. As pointed out in the preceding paragraphs, replication over time is a vital step in science.

Several limitations exist in the present study. First, although the present model was based on a large sample of Chinese early adolescents in the Hong Kong, the generalizability of the preferred model to adolescent population in mainland China and other cultural contexts should be cautious. Replication of the findings is needed. Second, as the present study was based on one cross-sectional data of a longitudinal research study, only causal inferences could be made. It is necessary to conduct studies utilizing the data from several waves to validate the predictive directionality of the variables in the models. Third, the effects of social desirability and self-serving biases should be taken into consideration in our students' self-reporting data. Notwithstanding the above limitations, the present study demonstrates that adolescents with a higher level of positive youth development were more satisfied with life and had lesser problem behaviour, with higher level of life satisfaction and lower level of problem behaviour mutually influencing each other. These replicated findings provide "an invaluable aid to scientific progress" (Reese 1999), a further advance in the literature on positive youth development, and an important basis for developing the future Chinese adolescents. In conjunction with other findings suggesting that positive youth development programs are able to promote positive behaviour but reduce problem behaviour in adolescents (Shek 2010c; Shek and Ma in press; Shek and Sun 2010a, b; Shek and Yu in press), it is recommended that regular curricular-based positive youth development programs should be implemented in the high school context and relevant policies facilitating the implementation should be devised.

Acknowledgments The preparation for this paper and the Project P.A.T.H.S. were financially supported by The Hong Kong Jockey Club Charities Trust.

Open Access This article is distributed under the terms of the Creative Commons Attribution Noncommercial License which permits any noncommercial use, distribution, and reproduction in any medium, provided the original author(s) and source are credited.

\section{References}

Anderson, J. C., \& Gerbing, D. W. (1988). Structural equation modeling in practice: A review and recommended two-step approach. Psychological Bulletin, 103, 411-423.

Bandura, A. (1997). Self-efficacy: The exercise of control. New York: Freeman.

Byrne, B. M. (1998). Structural equation modeling with LISREL, PRELIS, and SIMPLIS: Basic concepts, applications, and programming. Mahwah, NJ: Lawrence Erlbaum Associates, Inc.

Caprara, G. V., \& Steca, P. (2005). Self-efficacy beliefs as determinants of prosocial behavior conducive to life satisfaction across ages. Journal of Social and Clinical Psychology, 24(2), 191-217.

Catalano, R. F., Berglund, M. L., Ryan, J. A. M., Lonczak, H. S., \& Hawkins, J. D. (2004). Positive youth development in the United States: Research findings on evaluations of positive youth development programs. The Annals of the American Academy of Political and Social Science, 591, 98-124.

Child Trends (2003). Indicators of positive development conference summary. Retrieved March 1, 2005, from http://www.childtrends.org. 
Ciarrochi, J., Scott, G., Deane, F. P., \& Heaven, P. C. L. (2003). Relations between social and emotional competence and mental health: A construct validation study. Personality and Individual Differences, 35, 1947-1963.

Curran, P. J., West, S. G., \& Finch, J. F. (1996). The robustness of test statistics to nonnormality and specification error in confirmatory factor analysis. Psychological Methods, 1, 16-29.

Damon, W. (2004). What is positive youth development? Annals of the American Academy of Political and Social Science, 591, 13-24.

Desousa, C., Murphy, S., Roberts, C., \& Anderson, L. (2008). School policies and binge drinking behaviours of school-aged children in Wales-A multilevel analysis. Health Education Research, 23(2), 259-271.

Diener, E., Emmons, R. A., Larsen, R. J., \& Griffin, S. (1985). The satisfaction with life scale. Journal of Personality Assessment, 49, 71-75.

Diener, E., Suh, E. M., Lucas, R. E., \& Smith, H. L. (1999). Subjective well-being: Three decades of progress. Psychological Bulletin, 125, 276-302.

Fahs, P. S., Morgan, L. L., \& Kalman, M. (2003). A call for replication. Journal of Nursing Scholarship, 35(1), 67-71.

Fergusson, D. M., \& Boden, J. M. (2008). Cannabis use and later life outcomes. Addiction, 103, 969-976.

Finney, S. J., \& DiStefano, C. (2006). Non-normal and categorical data in structural equation modeling. In G. R. Hancock \& R. O. Mueller (Eds.), Structural equation modeling: A second course (pp. 269-312). Greenwich, CT: Information Age Publishing.

Gebauer, J. E., Riketta, M., Broemer, P., \& Maio, G. R. (2008). Pleasure and pressure based prosocial motivation: Divergent relations to subjective well-being. Journal of Research in Personality, 42, 399-420.

Georgiades, K., \& Boyle, M. H. (2007). Adolescent tobacco and cannabis use: Young adult outcomes from the Ontario child health study. Journal of Child Psychology and Psychiatry, 48(7), 724-731.

Heisel, M. J., \& Flett, G. L. (2004). Purpose in life, satisfaction with life, and suicide ideation in a clinical sample. Journal of Psychopathology and Behavioral Assessment, 26(2), 127-135.

Hu, L., \& Bentler, P. M. (1999). Cutoff criteria for fit indexes in covariance structure analysis: Conventional criteria versus new alternatives. Structural Equation Modeling, 6, 1-55.

Hu, L., Bentler, P. M., \& Kano, Y. (1992). Can test statistics in covariance structure analysis be trusted? Psychological Bulletin, 112, 351-362.

Hubbard, R., \& Vetter, D. E. (1996). An empirical comparison of published replication research in accounting, economics, finance, management, and marketing. Journal of Business Research, 35, $153-164$.

Jessor, R., Turbin, M. S., Costa, F. M., Dong, Q., Zhang, H., \& Wang, C. (2003). Adolescent problem behavior in China and the United States: A cross-national study of psychosocial protective factors. Journal of Research on Adolescence, 13(3), 329-360.

Jöreskog, K. G., \& Sörbom, D. (2006). LISREL 8.80: Structural equation modeling with the SIMPLIS command language. Chicago: Scientific Software International.

King, G. (1995). Replication, replication. Political Science and Politics, 28(3), 444-452.

Laudet, A. B., \& White, W. L. (2008). Recovery capital as prospective predictor of sustained recovery, life satisfaction, and stress among former poly-substance users. Substance Use and Misuse, 43, $27-54$.

Lent, R. W. (2004). Toward a unifying theoretical and practical perspective on well-being and psychosocial adjustment. Journal of Consulting Psychology, 51, 482-509.

Lent, R. W., Singley, D., Sheu, H. B., Gainor, K. A., Brenner, B. R., Treistman, D., et al. (2005). Social cognitive predictors of domain and life satisfaction: Exploring the theoretical precursors of subjective well-being. Journal of Consulting Psychology, 52(3), 429-442.

MacDonald, J. M., Piquero, A. R., Valois, R. F., \& Zullig, K. J. (2005). The relationship between life satisfaction, risk-taking behaviors, and youth violence. Journal of Interpersonal Violence, 20(11), 1495-1518.

McKnight, C. G., Huebner, E. S., \& Suldo, S. (2002). Relationships among stressful life events, temperament, problem behavior, and global life satisfaction in adolescents. Psychology in the Schools, 39(6), 677-687.

Narcotics Division. (2010). Resource kit on anti-drug education. Hong Kong: Narcotics Division, Security Bureau, Government of the Special Administrative Region, P.R.C.

Pavot, W., \& Diener, E. (2008). The Satisfaction with Life Scale and the emerging construct of life satisfaction. Journal of Positive Psychology, 3, 137-152.

Paxton, R. J., Valois, R. F., Huebner, E. S., \& Drane, J. W. (2006). Opportunity for adult bonding/ meaningful neighborhood roles and life-satisfaction among USA middle school students. Social Indicators Research, 79, 291-312. 
Reese, H. W. (1999). Strategies for replication research exemplified by replications of the Istomina study. Developmental Review, 19, 1-30.

Sam, D. L. (1998). Predicting life satisfaction among adolescents from immigrant families in Norway. Ethnicity \& Health, 3(1/2), 5-18.

Schumacker, R. E., \& Lomax, R. G. (2004). A beginner's guide to structural equation modeling (2nd ed.). Mahwah, NJ: Lawrence Erlbaum Associates.

Shek, D. T. L. (2004). Chinese cultural beliefs about adversity: Its relationship to psychological well-being, school adjustment and problem behavior in Chinese adolescents with and without economic disadvantages. Childhood, 11, 63-80.

Shek, D. T. L. (2010a). Positive youth development and behavioral intention to gamble among Chinese adolescents in Hong Kong. International Journal of Adolescent Medicine and Health, 21(1), 163-172.

Shek, D. T. L. (2010b). Quality of life of Chinese people in a changing world. Social Indicators Research, 95(3), 357-361.

Shek, D. T. L. (2010c). Using students' weekly diaries to evaluate positive youth development programs: Are findings based on multiple studies consistent? Social Indicators Research, 95, 475-487.

Shek, D. T. L., \& Ma, C. M. S. (2010). Dimensionality of the Chinese positive youth development scale: Confirmatory factor analyses. Social Indicators Research, 98(1), 41-59.

Shek, D. T. L., \& Ma, C. M. S. (in press). Impact of the Project P.A.T.H.S. in the junior secondary school years: Individual growth curve analyses. TheScientificWorldJournal.

Shek, D. T. L., Siu, A. M. H., \& Lee, T. Y. (2007). The Chinese positive youth development scale: A validation study. Research on Social Work Practice, 17, 380-391.

Shek, D. T. L., Siu, A. M. H., Lee, T. Y., Cheung, C. K., \& Chung, R. (2008). Effectiveness of the Tier 1 Program of Project P.A.T.H.S.: Objective outcome evaluation based on a randomized group trial. TheScientificWorldJournal, 8, 4-12.

Shek, D. T. L., \& Sun, R. C. F. (2009). Development, implementation and evaluation of a holistic positive youth development program: Project P.A.T.H.S in Hong Kong. International Journal on Disability and Human Development, 8(2), 107-117.

Shek, D. T. L., \& Sun, R. C. F. (2010a). Effectiveness of the Tier 1 Program of Project P.A.T.H.S.: Findings based on three years of program implementation. TheScientificWorldJournal, 10, 1509-1519.

Shek, D. T. L., \& Sun, R. C. F. (2010b). Subjective outcome evaluation based on secondary data analyses: The Project P.A.T.H.S. in Hong Kong. TheScientificWorldJournal, 10, 224-237.

Shek, D. T. L., \& Yu, L. (in press). Prevention of adolescent problem behavior: Longitudinal impact of the Project P.A.T.H.S. in Hong Kong. TheScientificWorldJournal.

Singh, K., Ang, S. H., \& Leong, S. M. (2003). Increasing replication for knowledge accumulation in strategy research. Journal of Management, 29, 533-549.

Suldo, S. M., \& Huebner, E. S. (2004). The role of life satisfaction in the relationship between authoritative parenting dimensions and adolescent problem behavior. Social Indicators Research, 66, 165-195.

Sun, R. C. F., \& Shek, D. T. L. (2010). Life satisfaction, positive youth development, and problem behaviour among Chinese adolescents in Hong Kong. Social Indicators Research, 95, 455-474.

Tsang, E. W. K., \& Kwan, K. M. (1999). Replication and theory development in organizational science: A critical realist perspective. Academy of Management Review, 24(4), 759-780.

Valois, R. F., Zullig, K. J., Huebner, E. S., Kammermann, S. K., \& Drane, J. W. (2002). Association between life satisfaction and sexual risk-taking behaviors among adolescents. Journal of Child and Family Studies, 11(4), 427-440.

Vecchio, G. M., Gerbino, M., Pastorelli, C., Del Bove, G., \& Caprara, G. V. (2007). Multi-faceted selfefficacy beliefs as predictors of life satisfaction in late adolescence. Personality and Individual Differences, 43, 1807-1818.

West, S. G., Finch, J. F., \& Curran, P. J. (1995). Structural equation models with nonnormal variables. In R. H. Hoyle (Ed.), Structural equation modelling: Concepts, issues, and applications (pp. 57-75). Thousand Oaks, CA: Sage.

Zullig, K. J., Ward, R. M., \& Horn, T. (2006). The association between perceived spirituality, religiosity, and life satisfaction: The mediating role of self-rated health. Social Indicators Research, 79, 255-274. 